\title{
Ser mentor em medicina: \\ uma visão arquetípica das motivações e transformações na jornada
}

Marina de Castro Nascimento Gonçalves ${ }^{1}$

Patrícia Lacerda Bellodi

GONÇALVES, M.C.N.; BELLODI, P.L. Being a mentor in medicine: an archetypal view on motivations and changes in the journey. Interface - Comunic., Saude, Educ., v.16, n.41, p.501-14, abr./jun. 2012.

Mentoring has been adopted in medical schools as a strategy to support and stimulate the professional development of medical students. However, the literature has seldom focused on the mentor, a crucial element of this archetypal relationship. The purpose of this paper was to understand the motivations of a group of mentors and to identify possible changes that take place over time. It is a qualitative study wherein 14 mentors involved in a Mentoring Program of a Medical School were interviewed. Mentors reveal the desire to recover the old, meaningful and close master-apprentice relationship.

Symbolically, they seek to stay in touch and take care of their "internal wounded student". Along the journey, mentors may - but not necessarily will - transform and be transformed by others.

Keywords: Mentoring. Mentor. Analytical psychology. Medical education.
A tutoria, na modalidade mentoring, tem sido adotada nas escolas médicas como estratégia para oferecer suporte pessoal e estimular o desenvolvimento profissional do futuro médico. O tutor, com papel de mentor, elemento crucial desta relação arquetípica, é pouco estudado em seu desenvolvimento pessoal. Este estudo buscou compreender as motivações de um grupo de tutores e identificar as possíveis transformações ocorridas ao longo do tempo. A investigação consistiu em um estudo qualitativo em que foram entrevistados 14 tutores de um Programa de Tutoria de uma Faculdade de Medicina. Há, entre os tutores, um desejo de restabelecer a antiga, significativa e próxima relação do mestre com o seu discípulo. Simbolicamente, buscam estar em contato com o seu "aluno interno ferido", e dele cuidar. Nessa jornada, podem - mas não necessariamente isso acontece a todos - transformar e ser transformados pelo outro.

Palavras-chave: Tutoria. Mentoring. Tutor. Psicologia analítica. Educação médica.

$$
\begin{array}{r}
1 \text { Programa de Pós- } \\
\text { Graduação, } \\
\text { Departamento de } \\
\text { Medicina Preventiva, } \\
\text { Faculdade de Medicina, } \\
\text { Universidade de São } \\
\text { Paulo (FMUSP). } \\
\text { Centro de } \\
\text { Desenvolvimento de } \\
\text { Educação Médica/ } \\
\text { CEDEM/FMUSP. } \\
\text { Av. Dr. Arnaldo, 455, } 2^{\circ} \\
\text { andar, sala 2354 } \\
\text { São Paulo, SP, Brasil. } \\
01.246-903 . \\
\text { marinacn@uol.com.br } \\
{ }^{2} \text { CEDEM, FMUSP. }
\end{array}
$$




\section{Introdução}

\section{Ser mentor}

Nas escolas médicas, onde a formação é marcada por intenso estresse acadêmico e emocional (Dyrbe et al., 2006), programas de Tutoria, na modalidade Mentoring, têm sido propostos como estratégia para oferecer suporte pessoal e estimular o desenvolvimento profissional ao futuro médico, especialmente a partir da década de 1990 (Frei, Stamm, Buddberg-Fischer, 2010).

Um tutor, com papel de mentor, é aquele que, por ser mais experiente, pode contribuir para a formação de um jovem iniciante, auxiliando-o no enfrentamento de problemas e nas escolhas e diferentes desafios encontrados ao longo do caminho de seu desenvolvimento.

$\mathrm{Na}$ Odisseia de Homero, Mentor era um sábio e fiel amigo de Ulisses, rei de Ítaca, e a ele foi confiado o cuidado de Telêmaco quando este partiu para a Guerra de Tróia. Durante a jornada deste jovem em busca de notícias de seu pai, Mentor o acompanha dando suporte, orientação e inspiração.

Um mentor pode ser considerado uma imagem arquetípica, isto é, ancestral, universal, simbolizando, em diferentes contextos, a figura que nos inspira, dá conselhos, e nos ajuda a atravessar a jornada (Daloz, 1986). Sem ser avaliador, nem assumindo papel de pai, amigo ou psicoterapeuta (Botti et al., 2008; Smith, Mc Allister, Crawford, 2001), um mentor pode ocupar um espaço social único para o jovem em busca de si mesmo (Levinson, 1978).

Vários estudos se preocupam em discutir os atributos de um bom mentor (Brad, 2002; Smith, Mc Allister, Crawford, 2001; Souba, 1999; Daloz, 1986), e reconhecem benefícios não só para os alunos, mas também para os mentores (Centeno, 2002; Freeman, 1998).

Entretanto, revisão recente de literatura aponta para o fato de que poucos estudos abordam a percepção do mentor sobre si mesmo e seu próprio desenvolvimento pessoal (Frei, Stamm, BuddbergFischer, 2010). Mesmo quando referidas, as mudanças percebidas pelos mentores em si mesmos são, em sua maioria, apresentadas apenas de forma descritiva, de modo ateórico, sem aprofundamento da dinâmica e do significado dessas transformações.

Nesse mesmo contexto, não há estudos, em Educação Médica, sobre as motivações em ser mentor. E, especialmente, não há estudos considerando que, à semelhança de outros encontros, conteúdos conscientes e inconscientes emergem da relação de Mentoring e podem impactar todos os envolvidos.

Este estudo busca investigar e compreender as vivências de um grupo específico de mentores, abordando-os segundo alguns conceitos teóricos da Psicologia Analítica, considerados importantes para esta questão, especialmente os arquétipos e os mitos no processo de individuação - com destaque para a Jornada do Herói.

\section{Os arquétipos}

Carl Gustav Jung, fundador da Psicologia Analítica, compreende o psiquismo como um sistema energético polarizado onde "todo consciente procura, talvez sem perceber, o seu oposto inconsciente, sem o qual está condenado à estagnação, à obstrução ou à petrificação" (Jung, 1989, p.45-6).

$\mathrm{O}$ inconsciente coletivo refere-se às camadas mais profundas e comuns a toda a humanidade: "Sua particularidade mais inerente é o caráter mítico. É como se pertencesse à humanidade em geral, e não a uma determinada psique individual" (Jung, 1987, p.33).

Os arquétipos são a base do inconsciente coletivo, definidos por Jung (1987) como um agrupamento definido de caracteres arcaicos, de caráter mitológico ou impessoal, agindo no homem de forma arbitrária, ou seja, não são controlados pela vontade. Podem ser considerados protótipos psíquicos que servem como matrizes para o desenvolvimento da psique. Funcionam como um centro de energia psíquica e se manifestam por meio dos símbolos (Penna, 2004).

São muitos os arquétipos na teoria junguiana, como, por exemplo, os da grande mãe, do velho sábio, do mestre-aprendiz, entre outros. Eles organizam as vivências humanas, são ativados durante a vida e, apesar de presentes em todos nós, sua intensidade e momento de manifestação são imensamente variáveis de um ser humano para outro (Byington, 1994). 
O arquétipo do herói, presente em vários mitos, representa a jornada de individuação do ser humano e a busca por autoconhecimento e superação das próprias dificuldades. Os heróis, geralmente, têm um nascimento complicado, estão ligados à ideia de luta, traduzida nos trabalhos a serem por eles realizados. São, geralmente, dotados de virtudes, mas não são perfeitos.

Sua jornada pode ser representada pela fórmula presente nos rituais de passagem, que envolve separação, iniciação e retorno.

O chamado à aventura significa o chamado do destino ou de um fenômeno que impulsiona o herói a sair dos caminhos comuns e conhecidos. Ele, após longos ritos iniciáticos, separa-se dos seus e inicia suas aventuras, vivenciando uma sucessão de provas, encontrando, também, figuras protetoras que o auxiliam na jornada. Ao final, retorna de sua travessia com aquilo que aprendeu na travessia, e "ao completar sua aventura circular, o herói acumulou energias suficientes para ajudar e outorgar dádivas inesquecíveis a seus irmãos" (Brandão, 2009, p.22).

\section{Psicologia analítica e Educação}

Em uma de suas obras, O desenvolvimento da personalidade, Jung (2002) destaca o papel da escola no desenvolvimento global do indivíduo, afirmando que o importante não é quanto a escola transmitiu de saberes, e sim se ela auxiliou o jovem a se tornar ele mesmo. A educação teria, assim, um papel fundamental no processo de individuação.

Jung distingue três tipos de educação: a coletiva, a individual e a educação pelo exemplo. A educação coletiva refere-se à transmissão de regras, valores e princípios de natureza coletiva e que garantem a vida em sociedade. A educação individual tem por objetivo o desenvolvimento da índole de cada um, valorizando suas singularidades, integrando o processo de individuação. A educação pelo exemplo ocorre espontaneamente, e de modo inconsciente, em todos os âmbitos da sociedade, para além das escolas.

Na concepção junguiana, educar é um processo relacional em que não é a ciência ou a técnica que contam, mas a personalidade do educador, pois o que está em jogo é a formação da consciência e da personalidade do educando (Teixeira, 2008). A essência da educação não é o que se ensina, mas o como se ensina: o menos importante é o conteúdo acadêmico ou o método, mas sim aquilo que o educador verdadeiramente é (Freitas, 2008).

Além disso, para Jung, a educação não deveria ser compreendida apenas como educação infantil, e muito menos como um processo que deva ser vivenciado unicamente pelos alunos, pois: "No adulto está oculta uma criança, uma criança eterna, algo ainda em formação e que jamais estará terminado, algo que precisará de cuidado permanente de atenção e de educação" (Jung, 2002, p.175).

Por esta razão, mais do que educar a criança (ou o aluno), é preciso educar o educador, o qual, antes de buscar conhecer metodologias, precisa conhecer tanto seus próprios processos psíquicos como os do seu educando (Teixeira, 2008).

Ampliar a consciência do educador sobre a presença desses elementos em sua relação com os alunos é tarefa importante para a qual a Psicologia Analítica acredita poder contribuir.

\section{A problemática deste estudo}

A partir da constatação da pequena atenção dada, na literatura em Mentoring, ao desenvolvimento pessoal dos próprios mentores, e das considerações teóricas, derivadas da Psicologia Analítica, sobre a importância do educador e de seus processos psíquicos, um estudo foi desenvolvido buscando compreender o mentor como "herói em sua jornada".

Foram investigadas as percepções e o significado atribuído por um grupo de mentores às suas vivências ao longo do tempo. O presente trabalho recorta, apresenta e discute, em especial, os dados relativos às motivações e transformações referidas pelos sujeitos ao longo do tempo. 


\section{Método}

A investigação consistiu em um estudo qualitativo exploratório junto a tutores de um Programa de Tutoria (Mentoring) de uma Faculdade de Medicina.

\section{Contexto}

A Faculdade de Medicina, cenário deste estudo, é uma das maiores escolas médicas brasileiras, de grande tradição em pesquisa científica e em formação nas diversas áreas de atuação médica. O corpo docente abrange os docentes da universidade e, também, médicos do hospital-escola e de outras unidades onde o ensino e os estágios são realizados. Recebe 175 alunos a cada novo ano.

Preocupada com a formação integral de seus alunos, implantou em 2001 um programa de Mentoring, denominado Programa Tutores.

O objetivo principal do Programa Tutores é estabelecer, para os alunos da faculdade, a figura de um tutor, com papel de mentor, que os acompanhará ao longo do curso. Em seus objetivos específicos, busca: proporcionar um vínculo mais intenso entre professores e alunos, promover a troca organizada de experiências entre os alunos dos diferentes anos, identificar problemas no curso e na formação dos alunos, e contribuir para o desenvolvimento global dos alunos.

Como na língua portuguesa não há tradução para a palavra Mentoring, utilizou-se, neste Programa, a palavra Tutoria para designar este tipo de relação, e a palavra tutor como sinônimo de mentor.

O Programa conta com um grupo de tutores, sendo cada um responsável, em média, por um grupo de 12 a 14 alunos. Todos os 1.080 alunos da Faculdade de Medicina têm um tutor de referência; sua participação é voluntária e estimulada por meio de créditos, registro no histórico escolar e certificado ao final do curso.

As características consideradas importantes para ser um tutor no Programa envolvem: ser médico, estar inserido no contexto da graduação, ter postura empática e bom relacionamento com os alunos, apresentar disponibilidade de tempo e disposição para participar do treinamento inicial e de supervisões periódicas.

\section{Sujeitos}

Quatorze sujeitos constituíram o grupo de sujeitos investigados (Quadro 1). Como estabelecido em pesquisas qualitativas, não se buscou representatividade numérica, e sim qualidade de informações nas entrevistas. O número de sujeitos foi considerado suficiente quando se percebeu redundância de informações ou saturação nas respostas produzidas por eles (Turato, 2003).

Procurou-se, intencionalmente, a heterogeneidade do grupo investigado quanto às seguintes variáveis: sexo, idade, especialidade (clínica, cirúrgica), presença nas supervisões (insatisfatória, regular, satisfatória); adesão dos alunos (insatisfatória, regular, satisfatória), e tempo no programa (veterano: no programa a partir de 2003, novato: no programa a partir de 2006).

Os dados foram coletados ao longo do segundo semestre de 2008 e em janeiro de 2009, quando o Programa contava com 81 tutores.

\section{Instrumento}

O instrumento de coleta de dados foi constituído por uma entrevista semiestruturada, com questões abertas, organizadas em um roteiro temático focado na experiência vivenciada pelos tutores ao longo do tempo.

Neste trabalho serão apresentados e discutidos os resultados de três destas questões:

1. Você está no Programa desde (personalizada para cada tutor) e com certeza tem muito a contar. Como você se percebe, como tutor, no início dessa caminhada e agora?

2. O que o motivou a ser tutor? 
3. Você acredita que os encontros tutor-aluno geraram mudanças em você ou na sua vida? Quais? Porquê?

Quadro 1. Sujeitos do estudo

\begin{tabular}{|l|c|c|l|l|l|l|}
\hline Tutor & Sexo & Idade & Especialidade & Tempo no Programa & Adesão à supervisão & Adesão dos alunos do grupo \\
\hline 1 & M & 55 & Cirurgia & Veterano & Satisfatória & Satisfatória \\
\hline 2 & F & 52 & Clínica & Novato & Baixa & Média \\
\hline 3 & F & 49 & Clínica & Veterana & Satisfatória & Insatisfatória \\
\hline 4 & M & 48 & Cirurgia & Veterano & Regular & Insatisfatória \\
\hline 5 & M & 61 & Cirurgia & Veterano & Regular & Insatisfatória \\
\hline 6 & M & 35 & Clínica & Novato & Regular & Satisfatória \\
\hline 7 & F & 54 & Clínica & Veterana & Satisfatória & Regular \\
\hline 8 & M & 44 & Clínica & Novato & Regular & Regular \\
\hline 9 & M & 40 & Cirurgia & Novato & Insatisfatória & Insatisfatória \\
\hline 10 & F & 50 & Clínica & Veterana & Regular & Insatisfatória \\
\hline 11 & F & 46 & Clínica & Novata & Regular & Satisfatória \\
\hline 12 & F & 50 & Clínica & Veterana & Insatisfatória & Insatisfatória \\
\hline 13 & M & 37 & Cirurgia & Novato & Insatisfatória & Insatisfatória \\
\hline 14 & M & 50 & Cirurgia & Novato & Satisfatória & Satisfatória \\
\hline
\end{tabular}

\section{Análise dos dados}

As entrevistas foram gravadas e transcritas na íntegra. O material coletado foi analisado segundo a técnica de análise de conteúdo (Bardin, 2007), com o estabelecimento de núcleos temáticos articulados aos objetivos do estudo.

O processo de análise envolveu, num primeiro momento, a leitura flutuante das transcrições para a familiarização com o material coletado e o estabelecimento de impressões sobre o fenômeno estudado.

Em seguida, novas leituras do material possibilitaram um aprofundamento no exame dos relatos e permitiram a identificação de categorias empíricas dentro dos temas abordados no roteiro de entrevista, os quais constituíram os eixos norteadores para a interpretação. A leitura foi realizada repetidamente até que as associações ficassem saturadas, isto é, sem novas informações relevantes (Dicicco-Bloom, Crabtree, 2006).

A categorização das respostas implicou a imersão do pesquisador nos dados obtidos, grifando trechos, fazendo anotações e observações sobre os conteúdos (Carlini-Cotrin, 1996), buscando identificar os núcleos de sentido presentes no material.

Neste estudo, a pesquisadora e sua orientadora realizaram leituras em paralelo do material e reuniram-se para discutir a construção e definição final, por meio de consenso, das respectivas categorias.

Foram selecionadas as expressões mais ilustrativas dos discursos dos entrevistados que continham os elementos geradores das categorias. As entrevistas foram numeradas conforme sua ordem da realização.

\section{Resultados}

\section{As motivações}

Durante as entrevistas, diversas motivações foram relatadas pelos tutores para justificar seu interesse em participar do Programa. 
Estas puderam ser compreendidas em dois grandes grupos: motivações relativas ao aluno (o aluno em si, o aluno como representante da juventude, o tutor quando aluno no passado) e as motivações relativas à instituição (oficializar uma função, colaborar com a formação, atualizar-se sobre a faculdade, retribuir as oportunidades recebidas).

Simbolicamente, as motivações para ser tutor podem ser compreendidas como o chamado para o início da jornada. Representam a saída de um lugar conhecido, seguro e confortável, para outro espaço, desconhecido e desafiador - no caso dos tutores, a saída do lugar de professor para o novo mundo das relações de Mentoring.

\section{O chamado do aluno}

\section{Quero maior proximidade}

A maioria dos tutores relatou o desejo de, por meio deste papel e atividade, estar mais próximo dos alunos. Buscam essa proximidade porque se ressentem da pequena interação com os alunos durante 0 cotidiano da formação. Mostram, em suas respostas, desejo de vínculo e relação continuada para além do contato breve e pontual como professor em sala de aula.

\footnotetext{
“Vontade de me aproximar dos alunos, de estar numa relação mais próxima, porque quando você dá aula são interações muito pontuais. Eu dei aula pra grupos grandes, dificilmente você conseguia criar vínculos ou conhecer as pessoas. Então a Tutoria, eu via assim, é um grupo que vai estar comigo, idealmente, vários anos, e aí eu vou poder ter uma proximidade maior". (Tutor 11)
}

“Na minha especialidade a gente tem um contato muito pequeno, diferente da Clínica Médica, da Pediatria, que tem um contato maior; então é uma questão de complementar esse contato". (Tutor 4)

"Eu gosto muito de estar com os alunos. Eu estou aqui por causa dos alunos, eu sempre quis ter contato com eles, basicamente foi a vontade de estar junto com eles." (Tutor 1)

\section{Quero contato com a juventude}

Vários tutores destacaram a satisfação de estar em contato com os jovens de hoje, com o que pensam, acreditam e aspiram. Esse contato os rejuvenesce, pessoal e academicamente, estando associado a sentimentos de alegria, espontaneidade e frescor:

"Eu fico observando, eu vejo o que os estudantes ficam falando, eu fico olhando, é essa parte que eu gosto: parece que eu tenho a idade deles...". (Tutor 1)

\footnotetext{
"Porque eu acho que você tem que ficar em contato com pessoas mais novas, é uma coisa muito saudável. Porque, na verdade, vai passando o tempo, você vai ficando mais velha... Os alunos nessa faixa etária, principalmente, quando você conversa com eles, eles têm muita coisa de positivo, né? Mesmo que eles estejam em conflito, é uma coisa mais alegre, estão sempre felizes". (Tutor 2)
}

\section{Quero oferecer o que não tive}

Muitos tutores apresentaram lembranças de situações emocionais difíceis durante a fase de aluno, especialmente situações de desamparo e insegurança. Acreditam que podem, a partir de suas experiências, contribuir para o enfrentamento de situações novas ou difíceis vividas pelos alunos, oferecendo o suporte que gostariam de ter recebido quando eram estudantes: 
"Você se lembra muito de como você era também, né? Por exemplo, a insegurança em fazer o exame de residência, como você se sentia em relação aos colegas. Você vê que é uma coisa muito comum, que todo mundo sente mais ou menos a mesma coisa, a mesma coisa que eu sentia na minha época, entendeu?". (Tutor 2)

"Eu vou me remetendo a cada coisa... Essa do primeiro contato com um paciente foi uma das mais fortes. Foi uma coisa que me pegou bastante, quando eu comecei a cuidar de pacientes: você está no $5^{\circ}$ ano da faculdade, eu tinha 21, 22 anos, sei lá, mas, esse é o seu paciente, então, ai meu Deus!". (Tutor 8)

"Eu me sinto bem em ajudar outras pessoas a ficarem menos angustiadas do que eu fui, quando eu tive que enfrentar algumas coisas da minha época de aluna e não tinha a quem recorrer". (Tutor 3)

"Uma coisa que eu tenho muito claro é a minha memória de aluna, de quando eu fui estudante, e eu tento na Tutoria fazer tudo o que não fizeram por mim, entendeu?". (Tutor 10)

No chamado do aluno, as respostas dos tutores reforçam observações do cotidiano e de estudos da área mostrando que a formação médica perdeu, ao longo do tempo, sua marca original de uma relação próxima e continuada. Segundo Woessner et al. (1998), atualmente, o contexto relacional atual da escola médica, devido ao número elevado de alunos e a competição acirrada entre eles, tem levado ao anonimato, ao distanciamento entre professores e alunos, e à solidão no enfrentamento dos problemas.

Reforçando tal constatação, Ramos-Cerqueira (1997), ao discutir a relação professor-aluno, ressalta a inexistência do espaço para a subjetividade, especialmente na escola médica, onde predomina o modelo autocrático e hierárquico do ciclo básico à pós-graduação. Segundo esta autora, é evidente a desigualdade na relação professor-aluno onde "ter o saber, ter o conhecimento, empresta poder a quem o tem e desqualifica aquele que não o possui, levando a um estilo de aprender em que a passividade e a atitude acrítica são as marcas" (Ramos-Cerqueira, 1997, p.188).

Programas de Mentoring surgem, e os tutores mostram reconhecer essa potencialidade ao apresentarem suas razões de engajamento na atividade, como possibilidade de resgate de uma relação professor-aluno mais particularizada, humanizada e integradora dos aspectos pessoais e profissionais dos estudantes (Bellodi, Martins, 2005).

O desejo de estar com os alunos na Tutoria revelou, também, necessidades de outra ordem, interna e subjetiva, nem sempre consciente.

Do ponto de vista da Psicologia Analítica, pode-se considerar que os professores são chamados a serem tutores para atender a demandas de seu par complementar, interno, nesta relação: a polaridade aluno. Ao referir esta motivação, o tutor, ocupando o polo do mestre, revela a busca inconsciente e compensatória de estar em contato com o seu oposto: o polo do aprendiz, que representa, neste caso, simbolicamente, o novo, o vigor.

Tal desejo mostra-se muito positivo, na medida em que, no caminho de formação do professor, é necessário, também, reconhecer-se aluno.

Ostetto (2007, p.204) destaca, nesse aspecto, que a educação nunca está finalizada, pois há sempre mais a ser expandido em termos de consciência e aprendizado e "há uma criança interna no professor que precisa ser cuidada".

Segundo este autor, quando o professor consegue perceber e cuidar desta criança, deste jovem aprendiz que existe em si, pode constelar no outro - isto é, a imagem arquetípica passa a se manifestar - o polo oposto, ou seja, reconhecer no aluno, também, alguém que possui um saber. Da mesma forma, o tutor, quando reconhece e valoriza o jovem, constela nele alguém com o qual poderá também aprender.

O contato com os alunos, simbolicamente, funciona como um elixir da juventude, promovendo a vivência de algo saudável, rejuvenescedor, promissor, positivo e criativo. Parece se constelar aqui o arquétipo do Puer (juventude eterna) que está ligado à possibilidade do novo, do futuro, da mudança. É 
positivo quando traz renovação, quando há espontaneidade, mas é negativo quando há fixação, ficando o indivíduo preso em um mesmo movimento, em uma mesma fase, não conseguindo passar para a fase adulta. O Puer vive uma vida provisória, uma vida de hipóteses/planos (um dia..), da qual o adulto, muitas vezes, tem saudade (Hillman, 2008).

Entretanto, se o contato com o aluno e com a juventude representa a possibilidade do novo, do crescimento, da revelação, por outro lado, mostra também a possibilidade de um começo insignificante, de impotência e desamparo (Ostetto, 2007).

Destacou-se, especialmente, na exploração das motivações, o fato de muitos tutores terem relatado experiências difíceis, intrínsecas à formação médica (as dificuldades de adaptação inicial ao curso, a sobrecarga de estudos, o contato com a morte, a insegurança no início da prática clínica, a angústia frente à comunicação de más notícias), mas que, se tivessem sido compartilhadas, poderiam ter sido elaboradas de maneira mais positiva e com menor sofrimento.

Do ponto de vista analítico, parece haver, assim, no engajamento com a Tutoria, a aproximação dos professores a um aluno interno ferido: um estudante que se sentiu perdido, desamparado, confuso. Ao desejarem oferecer agora, como tutores, o suporte e o amparo que não tiveram quando alunos, os professores parecem buscar a Tutoria também para cicatrizar algumas feridas: ao fazerem pelo outro - o aluno de hoje -, fazem também para si.

Tal motivação "reparadora" é considerada elemento fundamental da própria vocação médica e tem sido destacada em estudos sobre a escolha pela Medicina como profissão, especialmente no trabalho de Millan (2005). Segundo esse autor, ao discutirem as motivações inconscientes da escolha pela Medicina, alguns alunos de Medicina desejam oferecer aos outros, via profissão, o que gostariam de ter recebido (reparação do abandono) ou de ter dado (reparação da impotência) em outras situações.

\section{O chamado da instituição}

\section{Quero oficializar o que faço}

Alguns tutores, ao exercerem esta função, buscam uma maneira de oficializar um papel que acreditam já exercer de maneira informal na faculdade:

"Dentro da faculdade já existe um tutor informal que é o professor de Propedêutica. Então, pra mim não tinha muita diferença: fazer aquilo, ou fazer o que eu estou fazendo agora, é muito parecido, né?". (Tutor 3)

"Pela oportunidade de oficialmente fazer o que eu sempre fiz". (Tutor 10)

\section{Quero colaborar na formação}

Outros tutores se sentem comprometidos em colaborar com a formação global dos alunos:

“Eu acho que é muito importante um médico bem formado, para que depois ele aprenda a aprender sozinho. Não acho que você não precisa dar a informação, mas é mais importante você dar formação". (Tutor 7)

"Eu gosto da sensação de estar formando pessoas, eu gosto disso". (Tutor 8)

\section{Quero me atualizar}

Alguns tutores relatam que a atividade da Tutoria permite que eles permaneçam atualizados a respeito da própria instituição: 
"Se manter ligado às coisas da Faculdade através do contato com os alunos, eles te contam a maior parte das coisas que estão acontecendo". (Tutor 4)

“Eu perdi o pé de algumas coisas que estão acontecendo no dia-dia da Faculdade e a Tutoria é uma das coisas que me mantém informada". (Tutor 3)

\title{
Quero retribuir
}

Há tutores cujo vínculo com a instituição é de forte identificação, desejando continuar vinculados e retribuir à faculdade as oportunidades por ela dadas a eles:

\begin{abstract}
"Na verdade, eu gosto muito da faculdade. Eu acho que a gente cria, eu criei um laço com a Faculdade de Medicina e um laço com os alunos da Faculdade de Medicina, não com um aluno especificamente. Então, é uma maneira de eu continuar me sentindo útil pra Faculdade". (Tutor 13)

"Emprestar a minha experiência e a minha vivência, pelo fato de eu ter nascido, criado e evoluído dentro da Faculdade de Medicina, compartilhar essa minha experiência e vivência para facilitar a vida dos que vêm". (Tutor 5)

"Porque sou um exemplo muito típico do que é um aluno da faculdade. Fui presidente da Atlética, fui do Show Medicina, fui diretor de esportes, eu tive uma vida acadêmica muito rigorosa e na residência também, estou aqui desde que eu entrei na faculdade". (Tutor 4)
\end{abstract}

No chamado institucional, representado por aspectos ligados à faculdade, a atividade é, para alguns tutores, uma possibilidade de formalizar uma função e uma relação já vivenciada no cotidiano junto aos alunos. Outros tutores, considerando que a faculdade se preocupa em informar, mas não forma integralmente seus alunos, buscam, na atividade, a oportunidade de, como tutor, ser, de fato, um educador. Para eles, não basta transmitir conhecimento, é preciso formar o aluno discutindo valores, auxiliando no desenvolvimento de competências, incentivando uma atuação ética e comprometida.

Essas demandas revelam desejo de maior valorização da função docente e mostram-se relacionadas à configuração político-pedagógica da própria faculdade, onde o ensino é desenvolvido, em grande parte, por médicos do hospital-escola. Estes, apesar da intensa participação no dia a dia da formação, por não serem professores oficiais na instituição, não têm autonomia, nem poder de decisão, frente a muitos aspectos que dizem respeito à sua atuação.

Tal contexto é presente também em outras escolas médicas, como apresentado na investigação de Bulcão e Sayd (2003), junto a médicos de um hospital-escola do Rio de Janeiro, onde muitos deles mostraram ter assumido a função de ser professor de maneira acidental. Para alguns docentes, o tornarse professor é percebido como uma passagem natural de médico do hospital universitário a docente, como se "fosse inevitável que a assistência médica num hospital universitário estivesse, já de antemão, vinculada ao ensino" (Bulcão, Sayd, 2003, p.17).

Do ponto de vista analítico, a Tutoria parece oferecer, a alguns desses professores, outra persona, a de tutor, na busca por maior reconhecimento e legitimação institucional. Permite, também, traduzir um ideal formativo, indo ao encontro da valorização de uma formação médica menos conteudista e mais humanista e atitudinal.

Outro aspecto merece ser destacado: para alguns tutores, há uma forte identificação com a faculdade. Sujeito e instituição, criador e criatura, se entrelaçam e, se por um lado, sentimentos de gratidão são explicitados, algumas respostas revelam certa indiferenciação entre o sujeito e este mesmo espaço. Em uma leitura simbólica, a Faculdade de Medicina parece ocupar, para esses tutores, o lugar da Grande Mãe. O arquétipo materno representa o maternal, o feminino, o que cuida, o que proporciona condições de crescimento, transformação, mas pode também representar o devorador, sedutor e apavorante. Todos os símbolos, como salientou Jung (2008, p.92), "podem ter um sentido 
positivo, favorável, ou negativo e nefasto". Neste caso, pode-se considerar que a Faculdade de Medicina, em seu sentido negativo, poderia representar também, com sua força, a aniquilação da própria personalidade dos seus membros.

\section{As transformações}

\section{Mudanças? Sim!}

Muitos dos tutores entrevistados relataram mudanças em si mesmos, a partir da experiência com a Tutoria. Para esses tutores, a relação tutor-aluno possibilitou a revisão de si mesmos e do contexto em que se encontram, ampliou sua visão e abriu espaço para mudanças.

\section{Amadureci} visão:

Para alguns tutores, a transformação observada em si mesmos gerou amadurecimento e mudança de

\footnotetext{
"Mudei sim, mudei o meu jeito de pensar, mudei o jeito de pensar a faculdade, ampliei a minha visão sobre o nosso papel dentro desse processo de formação do aluno. E me tornei mais maduro e mais consciente de minhas atitudes". (Tutor 6)
}

"Acho que a gente amadurece. Vejo os meninos e começo a ter uma visão diferente, você melhora, amadurece, é gratificante". (Tutor 13)

\section{Mudei meu jeito}

Outros tutores revelaram mudanças em seu estilo de pensar e agir, com reflexão sobre seus valores:

\footnotetext{
"Acho que sim, não sei o quanto, mas acho que gerou leveza. Também me levou a pensar no que eu quero de verdade, conforme fui discutindo as coisas. Veja, é muito engraçado, eu fiquei como eles, pensando no que eu quero, o que eu vou fazer, tentando planejar, tentando realizar meus desejos. Porque no fim é tudo a mesma coisa: eu só tenho 20 anos mais...". (Tutor 8)

"Mudou até a minha linha de raciocínio. Eu sempre fui linear: primeiro, segundo, terceiro, raciocínio de cirurgião, né? Se tem duas linhas, eu vou daquela para aquela; se não tiver linha eu não sei andar, estou aprendendo, isso é muito legal". (Tutor 1)
}

A jornada, além das vicissitudes, também pode propiciar aprendizado e transformações ao Herói, tal como foi relatado por muitos tutores durante a entrevista. A maioria dos tutores reconhece que a tutoria contribui para um processo de amadurecimento e de desenvolvimento, propiciando uma visão mais ampla e compreensiva do mundo acadêmico e de relações humanas em geral.

Tal resultado confirma outros estudos que indicam que a relação de Mentoring beneficia também os tutores, sendo considerada uma via de mão dupla.

No estudo de Stenfors-Hayes et al. (2010) junto aos mentores do Karolinska Institute Teaching Hospital, a maioria dos entrevistados considerou que ser mentor levou a um maior interesse pelo ensino, incrementou sua relação com os alunos e promoveu reflexão a respeito de seus valores e práticas profissionais.

No Programa Tutores, cenário deste estudo, em avaliação junto a todos os tutores de 2004, estes já haviam reconhecido que aprenderam muito com a atividade, não só como professores e membros da instituição (melhor conhecimento dos alunos da faculdade e da faculdade como um todo, maior 
motivação e integração), mas, também, como pessoas (desenvolvimento de habilidades de comunicação, revisão de valores, renovação de idéias) (Bellodi, Martins, 2005).

No Programa de Mentoring do Curso de Medicina da USP - Ribeirão Preto, após um ano de funcionamento regular, os mentores também afirmaram que o programa estava sendo útil na formação docente (Colares et al., 2009).

Parece existir, com a Tutoria, uma possibilidade de integração de aspectos nem sempre conscientes, além de uma revisão de valores e atitudes não apenas na profissão, como também na vida em geral.

Tal integração é parte essencial do processo de Individuação e aponta para um aspecto muito importante nesta relação - o reconhecimento de que o jovem também tem algo a oferecer e a ensinar ao tutor: Tem um momento em que você percebe que a vida acadêmica tem sido generosa com você: "você tem sido mentor, mas num certo momento o aluno mentoreou você" (Centeno, 2002, p.1215).

\section{Mudanças? Não...}

Outros tutores, entretanto, não identificaram mudanças ou transformações derivadas da experiência. Alguns, por acreditarem que as vivências da Tutoria repetem experiências prévias semelhantes junto a alunos em outros contextos, não havendo, assim, a vivência de algo novo e transformador. Outros, por reconhecerem mudanças apenas nos alunos. Por fim, houve também o relato de não-mudança, acompanhado por um não querer qualquer transformação, uma vez que o novo, encontrado no caminho, não é reconhecido como positivo.

\section{Já fazia parte}

Alguns justificaram dizendo que este tipo de relação com os alunos há muito já está presente em seu cotidiano:

“Eu posso ser sincera? Igual, não muda muito, porque eu já tenho muito contato com os alunos ao longo da graduação". (Tutor 1)

"Na verdade, nesses dois, três anos, eu não senti nenhuma diferença, porque eu estou acostumado a lidar com os alunos há mais de 20 anos". (Tutor 14)

\section{Os alunos é que mudam}

Outros observam transformações apenas nos alunos:

“Eu não sei se houve mudanças não... Os alunos mudam, a gente observa uma grande mudança nos alunos. Eu, especialmente, não sei se mudei muito, acho que não...". (Tutor 7)

\section{Não há o que mudar}

E houve, ainda, aqueles que referiram não haver, em sua percepção, o que ser transformado em si:

“Bom, eu sou eu, eu não mudei, nem a tutoria me mudou. Não mudou o meu jeito de ser, não acho correto o jeito dos alunos serem hoje em dia, então eu continuo o mesmo. Eu acho que o ser é mais importante do que o ter e tento passar isso...". (Tutor 5)

Do ponto de vista analítico, é interessante pensar nesse último relato a partir da relação entre os arquétipos do Senex e do Puer, onde há um encontro do histórico com o novo, ou daquele que é a imagem da história e da verdade permanente com quem transcende a história - o encontro do Pai Tempo com o Jovem Eterno (Hillman, 2008). O aspecto negativo do Senex, talvez aqui constelado, é o processo de endurecimento da consciência, o distanciamento da vida, a unilateralidade gerando um 
egocentrismo. Nesse sentido, não há a integração com o Puer, fizando-se o Senex num tempo histórico que o impede de assimilar o que pode existir de valor no que é novo (Hillman, 2008).

Não se transformar, não se perceber transformado ou não desejar ser transformado, é resultado que merece atenção e trabalho junto aos tutores.

Como destacado por Galiás (1989), é fundamental a percepção de que "como professores, estamos nos desenvolvendo, ou seja, estruturando também a nossa personalidade e não somente do aluno" (p.90). Somente na medida em que o professor se percebe incluído no processo de desenvolvimento, juntamente com seu aluno, é que outras atitudes do professor - neste caso, do tutor -, em relação ao seu papel podem decorrer.

\section{Conclusões}

Neste estudo, a proposta de investigar vivências de tutores, participantes do Programa Tutores de uma Faculdade de Medicina, partiu da percepção de que é essencial discutir aspectos subjetivos na relação com o aluno e, especialmente, consigo mesmo.

A análise de tais vivências, numa perspectiva simbólica e analítica, ao mesmo tempo articulada ao campo do Mentoring, permite compreender aspectos importantes da Jornada do Tutor, e diz respeito às suas motivações e transformações ao longo do tempo.

Há, entre os tutores, um desejo de restabelecer a antiga, significativa e próxima relação do mestre com o seu discípulo, da qual os professores de hoje referem sentir falta; eles valorizam o ser docente no seu sentido maior e, por meio desse papel, reafirmam seu vínculo com a instituição, à qual são especialmente gratos: a Faculdade de Medicina.

Simbolicamente, buscam estar em contato com o seu aluno interno ferido, e dele cuidar. O aluno de hoje, seu par na relação de tutoria, permite ao tutor um encontro e um reencontro: reparador do passado e, ao mesmo tempo, rejuvenescedor e que o atualiza quanto ao presente.

Nessa jornada podem - mas não necessariamente isso acontece a todos - transformar e ser transformados pelo outro e aprender com a experiência.

Na compreensão da relação de Mentoring e de seus efeitos é fundamental considerar as motivações dos tutores em estarem juntos aos alunos, com especial atenção para suas determinações internas e nem sempre conscientes.

Igualmente importante é ajudá-los a reconhecer não apenas as recompensas da jornada, mas, também, as resistências e as dificuldades em se transformarem com ela.

A Psicologia Analítica pode contribuir, com seu referencial teórico, especialmente por meio do conceito de arquétipos, para o avanço conceitual e prático do Mentoring nas escolas médicas.

\section{Colaboradores}

Os autores trabalharam juntos em todas as etapas do manuscrito.

\section{Referências}

BARDIN, L. A análise de conteúdo. Lisboa: Edições 70, 2007.

BELLODI, P.L.; MARTINS, M.A. Tutoria: mentoring na formação médica. São Paulo: Casa do Psicólogo, 2005.

BYINGTON, CAB. A missão de Seu Gabriel e o arquétipo do chamado: um estudo da Psicologia Simbólica. Junguiana, n.12,p.110-33, 1994. 
BOTTI, S.H.O. et al. Preceptor, supervisor, tutor e mentor: quais são seus papéis? Rev. Bras. Educ. Med., v.32, n.3, p.363-73, 2008.

$B R A D, J . W$. Intentional mentor: strategies and guidelines for the practice of mentoring. Prof. Psychol. Res. Pract., v.33, n.1, p.88-96, 2002.

BRANDÃO, J.S. Mitologia grega. Petrópolis: Vozes, 2009.

BULCAO, L.G.; SAYD, J.N. As razões da escola médica: sobre professores e seus valores - os valores dos médicos e os impasses da escola médica. Physis, v.13, n.1, p.11-38, 2003.

CARLINI-COTRIN B. Potencialidades da técnica qualitativa: grupo focal em investigação sobre abuso de substâncias. Rev Saúde Pública. v.30, p.285-93, 1996.

CENTENO, A.M. How to enjoy your mentees' success and learn from it. Med. Educ., v.36, n.12, p.1214-5, 2002.

COLARES, M.F.A. et al. Mentoring for junior medical students. Rev. Bras. Educ. Med., v.33, n.4, p.670-5, 2009.

DALOZ, L. Effective teaching and mentoring: realizing the transformational power of adult learning experiences. San Francisco: Jossey-Bass Higer and Adult Education Series, 1986.

DICICCO-BLOOM B, CRABTREE B. The qualitative research interview. Med Educ., v.40, p.14-21. 2006.

DYRBE, L.N. et al. Systematic review of depression, anxiety, and other indicators of psychological sistress among U.S. and Canadian medical students. Acad. Med., v.81, n.4, p.354-73, 2006.

FREEMANN, R. Mentoring in general practice. Oxford: Butteworth-Heinemann, 1998.

FREI, E.; STAMM, M.; BUDDEBERG-FISCHER, B. Mentoring programs for medical students - a review of the PubMed literature 2000 - 2008. BMC Med. Educ., v.10, n.32, p.1-14, 2010.

FREITAS, L.V. Jung e a educação: um caleidoscópio. Rev. Educ. Jung Pensa Educ., n.8, p.68-75, 2008.

GALIÁS, I. Ensinar-aprender: uma polaridade no desenvolvimento simbólico. Junguiana, n.7, p.89-100,1989.

HILLMAN, J. O livro do Puer: ensaios sobre o arquétipo do Puer Aertunus. São Paulo: Paulus, 2008.

JUNG, C.G. Os arquétipos e o inconsciente coletivo. 6.ed. Petrópolis: Vozes, 2008.

O desenvolvimento da personalidade. Petrópolis: Vozes, 2002.

Psicologia do inconsciente. Petrópolis: Vozes, 1989.

O eu e o inconsciente. Petrópolis: Vozes, 1987.

LEVINSON, D.J. The seasons of a man's life. New York: Ballantine Books, 1978.

MILLAN, L.R. Vocação médica: um estudo de gênero. São Paulo: Casa do Psicólogo, 2005. 
OSTETTO, L.E. Na jornada de formação: tocar o arquétipo do mestre-aprendiz. Pro-Posições, v.18, n.3, p.195-210, 2007.

PENNA, E.M.D. A imagem arquetípica do curador ferido no encontro analítico. São Paulo: Pontifícia Universidade Católica, 2004. [Texto da disciplina Teorias e Técnicas Psicoterapêuticas].

RAMOS-CERQUEIRA, A.T.A. A prática pedagógica como processo de comunicação: a relação professor-aluno como eixo: o ponto de vista psicológico. Interface - Comunic., Saude, Educ., v.1, n.1, p.187-92, 1997.

SMITH, L.S.; MCALLISTER, L.E.; CRAWFORD, C.S. Mentoring benefits and issues for public health nurses. Public Health Nurs., v.18, n.20, p.101-7, 2001.

SOUBA, W.W. Mentoring young academic surgeons, our most precious asset. J. Surg. Res., v.82, n.2, p.113-20, 1999.

STENFORS-HAYES, T. et al. Being a mentor for undergraduate medical students enhances personal and professional development. Med. Teach., v.32, n.2, p.14853, 2010.

TEIXEIRA, M.C.S. O "pensamento pedagógico" de Jung e suas implicações para a educação. Rev. Educ.: Jung Pensa Educ., n.8, p.18-29, 2008.

TURATO, E.R. Tratado da Metodologia da Pesquisa Clínico Qualitativa. Rio de Janeiro: Vozes, 2003.

WOESSNER, R. et al. Faculty mentoring programme - ways of reducing anonymity. Med. Educ., v.32, n.4, p.441-3, 1998.

GONÇALVES, M.C.N.; BELLODI, P.L. Ser mentor en medicina: una visión arquetípica sobre las motivaciones y las transformaciones en la jornada. Interface - Comunic., Saude, Educ., v.16, n.41, p.501-14, abr./jun. 2012.

Las Escuelas de Medicina han adoptado la tutoria, en la modalidad mentoring, como una estrategia de apoyo y estímulo para el desarrollo profesional del futuro médico. Hay poca investigación sobre el tutor, que es un elemento crucial en esta relación arquetípica. Este estudio trata de comprender las motivaciones de un grupo de tutores e identificar los posibles cambios que ocurren en el transcurso del tiempo. Se trata de un estudio cualitativo en que se entrevistó a 14 tutores del Programa de Tutoría de una Faculdad de Medicina. Los tutores desean restablecer la antigua relación, significativa y cercana, entre el maestro y su discípulo. Simbólicamente, buscan estar en contacto y cuidar a su "estudiante interno herido". En este camino, los tutores pueden, pero no necesariamente les pasa a todos, transformar y ser transformados por el otro.

Palabras clave: Tutoría. Tutor. Mentoring. Psicología analítica. Educación médica. 